\title{
Altered platelet indices as potential markers of severe and complicated malaria caused by Plasmodium vivax: a cross-sectional descriptive study
}

\author{
Fábio A Leal-Santos*, Soraya BR Silva, Natasha P Crepaldi, Andréia F Nery, Thamires OG Martin, \\ Eduardo R Alves-Junior and Cor JF Fontes
}

\begin{abstract}
Background: This study described altered platelet indices in patients with acute malaria caused by Plasmodium vivax and determined whether these alterations are associated with warning signs of severe and complicated malaria.

Methods: A total of 186 patients attending the Malaria Clinic at the University Hospital from the Federal University of Mato Grosso, Brazil, between 2008 and 2013 were included in this study. After parasitological confirmation of exclusive infection by P. vivax, blood cell counts and platelet indices were determined. Disease gravity was evaluated on the basis of classic signs of Plasmodium falciparum severe malaria, including severe anemia, or by changes in serum levels of glucose, bilirubin, aminotransferases and creatinine at the time of the patient's admission. Patients with a longer duration of symptoms or those identified as primo infected were considered potential candidates for evolution into the severe form of malaria.

Results: The mean platelet volume (MPV), platelet distribution width (PDW), and plateletcrit (PCT) values exhibited significant variability. A significant inverse relationship was observed between parasitaemia and PCT. Patients with warning signs for evolution into severe disease, with primo infection, or presenting with symptoms for over three days had the highest MPV and PDW. The adjusted analyses showed the presence of warning signs for the development of severe and complicated malaria remained independently linked to elevated MPV and PDW.

Conclusion: Altered platelet indices should be analysed as potential markers for the severity of malaria caused by P. vivax. Future studies with appropriate methodology for prognostic evaluation could confirm the potential use of these indices in clinical practice.
\end{abstract}

Keywords: Malaria, Plasmodium vivax, Platelet indices

\section{Background}

Several clinical complications have been described in malaria caused by Plasmodium vivax, including severe anaemia, cerebral malaria, acute pulmonary oedema, and multi-organ failure [1]. Although thrombocytopaenia is often reported, the occurrence of bleeding is rare in these patients [2].

\footnotetext{
* Correspondence: alexandre3025@gmail.com

Malaria Clinic, University Hospital of Federal University of Mato Grosso, Rua Luis Phelippe Pereira Leite, s/n, Alvorada, Cuiabá (MT) CEP: 78048-902, Brazil
}

Changes in platelet counts during acute malaria are commonly reported in the medical literature, especially in Plasmodium falciparum infections; such changes are a major cause of concern to clinicians because such cases are more likely to evolve into serious and complicated disease cases [3,4]. However, many recent studies have also found thrombocytopaenia associated with $P$. vivax [5-7]. In general, the underlying mechanisms of thrombocytopaenia in malaria are peripheral destruction, excessive sequestration of platelets in spleen, and excessive use of platelets associated with the disseminated intravascular coagulation 
phenomenon [8]. In addition to the reduction in the number of platelets, platelet function is also compromised in these patients; this is generally evidenced by changes in the volume and other features of platelet cells [9].

Moreover, in addition to their function in haemostasis, platelets play an important role in the inflammatory response [10]. Changes in platelet counts during bacterial infections are reported to be associated with enhanced disease severity and mortality [11]. Furthermore, platelet activation alters the morphology of these cells, which can be evaluated on the basis of mean platelet volume (MPV) and platelet distribution width (PDW) [12]. Another platelet parameter is plateletcrit (PCT), which is a reliable measurement of platelet biomass because it combines the MPV with the absolute platelet count [13]. MPV, PDW and PCT can be altered in patients with cardiovascular [13] and infectious diseases such as pulmonary tuberculosis [14]. All of these indices are considered markers of platelet activation $[9,15]$ and are altered in different clinical conditions [16-18]. Nevertheless, little is known about the alterations in these indices in malaria, especially in infections with $P$. vivax.

Some studies reported MPV to be elevated in malaria $[4,19,20]$. Furthermore, the validity of this finding for the diagnosis of acute malaria was recently tested in suspected cases in India [21]. However, the relationship between this increase and the clinical outcome of malaria infection remains controversial $[19,22]$. Furthermore, there is no available information about the relationship between altered PDW or PCT and the severity of malaria caused by P. vivax.

The present study aimed to determine the frequency and factors associated with alterations in platelet indices in patients with malaria caused by $P$. vivax, as well as their associations with clinical and laboratory indicators of severe and complicated malaria outcomes.

\section{Methods}

This is a cross-sectional descriptive study based on the clinical and laboratory data of 186 patients with acute malaria caused by $P$. vivax who attended the Malaria Clinic at the University Hospital of the Federal University of Mato Grosso between 2008 and 2013. Data were collected on both ways: on a standardized form from 50 patients and extracted from the records of the remaining ones. Patients with exclusive $P$. vivax infection were eligible to participate in this study. All the patients underwent haemogram and blood biochemical analyses at their first appointment. Malaria was diagnosed on the basis of the microscopic examination of Giemsa-stained thick smears. All blood cell counts were determined using a same automated equipment (Pentra 80; Horiba Medical, Montpellier, France), which provides results regarding MPV, PDW, and PCT. The normal ranges for MPV, PDW and PCT provided for this equipment are $7.0 / \mu \mathrm{m}^{3}-10.5 / \mu \mathrm{m}^{3}, \quad 11 \%-18 \%$ and $0.15 \%-0.50 \%$, respectively.

Blood samples were continuously agitated after collection. To avoid interference in the analysed parameters, the time between blood sample collection and cell counting was ensured to be shorter than 60 minutes. All the participants signed an informed consent and underwent a detailed clinical evaluation by a team physician prior to participating. Information about the number of previous malaria infections and time of symptom onset was collected from all the patients.

Potential severe and complicated malaria caused by $P$. vivax was defined by the presence of one or more of the classic signs used as predictors of $P$. falciparum severity recommended by the World Health Organization [23] or the following changes in blood haematology or biochemical parameters at the time of patient's admission: body temperature $\geq 41^{\circ} \mathrm{C}$, dyspnoea, arterial hypotension, serum creatinine level $>1.5 \mathrm{mg} / \mathrm{dL}$, hypoglycaemia, hyperbilirubinaemia and haemoglobin $<7 \mathrm{~g} / \mathrm{dL}$ or haematocrit $<20 \%$. Moreover, primo infection and reporting symptoms that persisted for longer than three days were also considered potential risk factors for evolution into severe disease.

The data were analysed by the Stata version 12 software. The Mann-Whitney non-parametric test was used to analyse the association between platelet indices with the presence/absence of markers for severe or complicated malaria caused by $P$. vivax. Spearman's correlation coefficients were calculated to evaluate the relationships between platelet indices and parasitaemia. Multivariate logistic regression models were constructed with each parameter as a dependent variable to analyse the independence of the associations between severity and platelet indices. For this purpose, MPV, PDW, and PCT were stratified into two groups, namely above and below the median. The reason to use these strata was the large range of the normal platelet indices. The backward stepwise method was used to include all the studied variables in the model. The level of significance was set at $p<0.05$. This study was approved by the Research Ethics Committee of Julio Müller University Hospital (no. 242,721).

\section{Results}

The patients had a median age of 37,5 years and mean (SD) of 37.7 (14.7) years, and 145 (78.0\%) were men. The elapsed time between symptom onset and the diagnosis of malaria ranged from one to 60 days (median $=5$ days), with a mean (SD) of 7.1 (8.6) days. However, malaria was only diagnosed after 96 hours (i e, four days after symptom onset) in $54.4 \%$ of patients. At the time of diagnosis, $56.1 \%$ of the patients had fever. Twenty-one patients (11.3\%) had 
Table 1 Clinical and laboratory characteristics of patients with malaria caused by Plasmodium vivax

\begin{tabular}{|c|c|c|c|}
\hline Characteristics & & $n$ & $\%$ \\
\hline \multirow[t]{4}{*}{ Age (years) $(n=182)$} & $0-12$ & 5 & 2.7 \\
\hline & $13-49$ & 139 & 76.4 \\
\hline & $\geq 50$ & 38 & 20.9 \\
\hline & & \multicolumn{2}{|c|}{ Mean (SD), 37.7 (14.7) } \\
\hline \multirow[t]{2}{*}{ Sex } & Male & 145 & 78.0 \\
\hline & Female & 41 & 22.0 \\
\hline \multirow[t]{4}{*}{ Days with symptoms $(n=167)$} & 1 & 18 & 10.8 \\
\hline & $2-4$ & 58 & 34.7 \\
\hline & $>4$ & 91 & 54.5 \\
\hline & & \multicolumn{2}{|c|}{ Mean (SD), 7.1 (8.6) } \\
\hline \multirow[t]{2}{*}{ Fever at diagnosis $(n=157)$} & Yes & 88 & 56.1 \\
\hline & No & 69 & 43.9 \\
\hline \multirow[t]{2}{*}{ Indication of severity } & Yes & 21 & 11.3 \\
\hline & No & 165 & 88.7 \\
\hline Parasitaemia/mm ${ }^{3}(n=172)$ & & \multicolumn{2}{|c|}{ Mean (SD), 7,256 $(11,147)$} \\
\hline
\end{tabular}

Variation in the numbers of individuals is due to missing information.

at least one warning sign of severe and complicated malaria, including hyperpyrexia, severe anaemia, arterial hypotension, and elevated serum creatinine. The mean parasitaemia level observed in 186 patients was 7,256 $(11,147)$ parasites per $\mathrm{mm}^{3}$ blood (median $\left.=4,186\right)$. No patient reported using medicines with the potential to interfere with platelet indices (Table 1).

The haematological evaluation of all the patients showed a mean haemoglobin level of 12.9 (2.0) g/dL, mean haematocrit level of $38.5 \%$ (5.5\%), and mean leukocyte count of $6,278(6,323)$ leukocytes $/ \mathrm{mm}^{3}$. The mean platelet count was $114,823(76,761)$ cells $/ \mathrm{mm}^{3} ; 16.7$ and $60.7 \%$ of the patients exhibited counts fewer than
$50,000 / \mathrm{mm}^{3}$ and between $50,000 / \mathrm{mm}^{3}$ and $150,000 / \mathrm{mm}^{3}$, respectively. The MPV was $9.3(1.0) \mu \mathrm{m}$, mean PDW was $17.5 \%(3.36 \%)$, and mean PCT was $0.104 \%$ (0.066\%). All the blood haematological parameters were done in a same automatic equipment.

Potentially more serious cases, that is, primo-infected patients, exhibited significantly higher MPV and PDW ( $p=0.0003$ and $p=0.0003$, respectively) and signs of gravity ( $p=0.042$ and $p=0.036$, respectively). Conversely, patients with three or more days of symptoms had lower PCT ( $p=0.045$; Table 2$)$. A weak but statistically significant negative correlation was observed between parasitaemia and PCT $(\mathrm{r}=-0.28 ; p=0.0002)$. However, no significant correlation was observed between parasitaemia and MPV or PDW (Figure 1).

Adjusted models were constructed for each platelet parameter, which were categorized as higher or lower the median. Variables exhibiting significant associations in the univariate analysis were included in the model in addition to age and sex. After adjustments, primo infection and the presence of warning signs for severe malaria were independently associated with the highest MPV. Conversely, PDW remained associated with the number of previous malaria infections and the presence of signs of gravity. Only the longest duration of symptoms remained associated with the lowest PCT (Table 3).

\section{Discussion}

In the present study, the analysis of the platelet indices in 186 patients with malaria caused by $P$. vivax revealed a high frequency of thrombocytopaenia and changes in MPV, PDW, and PCT. The high frequency of warning signs of severe malaria cases can be explained by the fact that this study was conducted in a reference hospital for malaria diagnosis and treatment.

Table 2 Associations between platelet indices and clinical signs of severity in the patients with Plasmodium vivax malaria

\begin{tabular}{|c|c|c|c|c|}
\hline & & \multicolumn{3}{|c|}{ Platelet parameter } \\
\hline & & \multicolumn{3}{|l|}{ Mean (SD) } \\
\hline & & MPV $\left(\right.$ per $\left.\mu \mathrm{m}^{3}\right)$ & PDW (\%) & PCT (\%) \\
\hline \multirow[t]{3}{*}{ First infection } & Yes & $9.77(0.98)$ & $19.87(4.61)$ & $0.086(0.046)$ \\
\hline & No & $9.09(0.94)$ & $16.85(2.89)$ & $0.102(0.053)$ \\
\hline & $p$ & 0.0003 & 0.0003 & 0.1165 \\
\hline \multirow[t]{3}{*}{ Time of symptom onset } & $>3$ days & $9.32(1.03)$ & $17.93(3.75)$ & $0.091(0.055)$ \\
\hline & $\leq 3$ days & $9.12(0.86)$ & $16.77(2.81)$ & $0.104(0.044)$ \\
\hline & $p$ & 0.166 & 0.065 & 0.045 \\
\hline \multirow[t]{3}{*}{ Warning signs for severity } & Present & $9.62(1.12)$ & $18.98(3.64)$ & $0.079(0.036)$ \\
\hline & Absent & $9.21(0.95)$ & $17.35(3.46)$ & $0.105(0.067)$ \\
\hline & $p$ & 0.042 & 0.036 & 0.084 \\
\hline
\end{tabular}



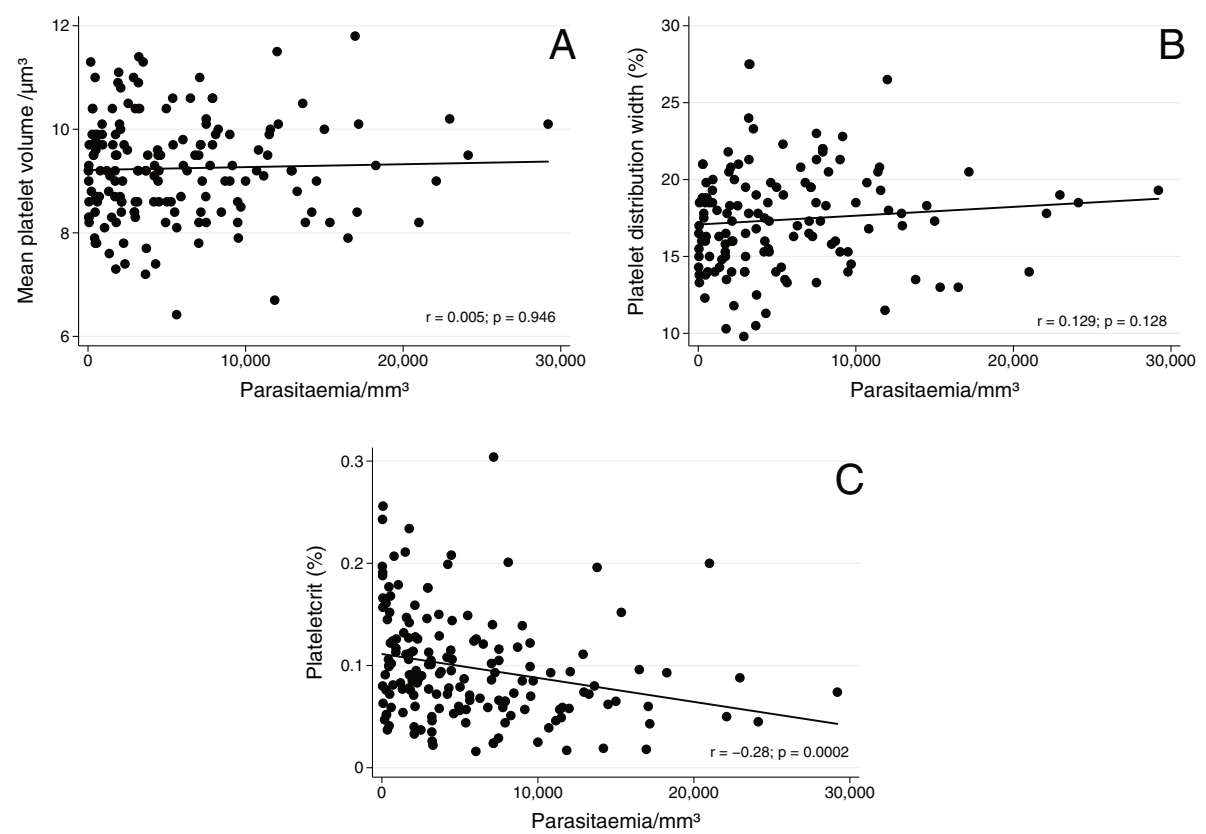

Figure 1 Relationships between parasitic density and other variables in the patients with malaria caused by Plasmodium vivax. Parasitic density versus MPV (A), PDW (B), and PCT (C).

MPV was higher than the median value in $46.2 \%$ of the patients, which is a higher percentage than that observed in patients infected with $P$. falciparum (25\%) in Saudi Arabia [24] but similar to that reported by Franklin et al. [6] and Coelho et al. [20] regarding patients infected with $P$. vivax in the Amazon region. Increased MPV in malaria has been observed in other studies $[4,19]$. The validity of using such an increase in MPV in the diagnosis of acute malaria in suspected cases was recently tested in India; the authors concluded that a MPV exceeding $8 \mu^{3}$ exhibits a sensitivity and specificity of 70.8 and $50.4 \%$ for the diagnosis of malaria, respectively [21].

It is well known that non-immune individuals are more susceptible to developing severe malaria. Furthermore, the delay of onset of malaria treatment is directly associated with severe disease outcomes [23]. In this study, changes in platelet indices predominated in the patients with any indicator of severe malaria caused by $P$. vivax, such as primo infection, longer symptom duration, and the presence of clinical signs and laboratory indicators of severe malaria. Larger platelets are metabolically and enzymatically more active and have a more important role in the inflammatory process [25]. Elevated MPV has also been described in patients with severe sepsis and is explained by the quick splenic and medullary release of large volumes of platelets in response to the increased demand for these cells [16]. In fact, studies in humans and rats showed that large platelets are functionally more active and have a lower threshold for aggregation and the release of their activity $[9,16]$. In bacterial diseases, increased MPV is associated with invasive infection or refractoriness to antimicrobial treatment [26].

It is well known that PDW is linearly correlated with MPV in normal individuals [12]. However, it is unlikely that the increased PDW observed in the present study was solely a consequence of increased MPV. Platelet width is reported to be greatly heterogeneous even with normal MPV in myeloproliferative diseases [12], eclampsia [27], acute coronary syndrome and heart failure [28], vascular micro-occlusion of sickle-cell disease [29], and bacteraemia [9,16,26]. Only one study mentions MPV in malaria and concluded that this parameter can be considered a predictor of acute infection by $P$. falciparum [21]. In all of these studies, the platelet activation was considered the main mechanism inducing the elevation of MPV and PDW.

Low mean PCT was also verified in the patients with acute malaria in the present study. However, little is known about PCT during the courses of various diseases. Thus, PCT is the most neglected haematological parameter in clinical practice and one of the least often reported in publications in the biomedical literature. PCT alterations are observed in some clinical conditions such as coronary ischemia [13], diabetes mellitus [30], pulmonary tuberculosis [31], sleep apnea [32], and inflammatory bowel disease [33].

The preference of $P$. vivax for infecting only young cells in peripheral blood avoids the occurrence of high 
Table 3 Multivariate logistic regression analysis of the associations between platelet indices, demographic variables, and severity indicators

\begin{tabular}{|c|c|c|c|}
\hline Variable & Odds ratio & $95 \% \mathrm{Cl}$ & $p$ \\
\hline \multicolumn{4}{|l|}{$M P V$} \\
\hline Primo infection & 2.72 & $1.16-6.38$ & 0.039 \\
\hline Presence of warning signs for severity & 3.47 & $1.02-11.75$ & 0.033 \\
\hline \multicolumn{4}{|l|}{ PDW } \\
\hline Previous episodes of malaria & 0.91 & $0.85-0.97$ & 0.004 \\
\hline Presence of warning signs for severity & 5.44 & $1.20-24.78$ & 0.028 \\
\hline \multicolumn{4}{|l|}{$P C T$} \\
\hline Time with symptoms (days) & 2.46 & $1.11-5.46$ & 0.038 \\
\hline
\end{tabular}

parasitic density in vivax malaria [34]. However, we found a negative correlation between the level of parasitaemia and PCT. Once the PCT is a measure of the platelet biomass, this finding may be explained by the concomitant thrombocytopenia, which is also known to be associated with thrombocytopenia associated with P. vivax infections $[35,36]$.

This study has some limitations that should be mentioned. First, other conditions causing platelet count reduction and changes in platelet indices were not systematically investigated. However, the changes in the studied parameters as part of post-treatment evaluation suggest that malaria was the most likely cause of the observed alterations.

\section{Conclusion}

In conclusion, this study shows that platelet indices were altered during acute and symptomatic infection by $P$. vivax. The elevation of MPV and PDW, and reduction of PCT are related to known potential risk factors for evolution into severe malaria, such as primo infection, longer symptom duration, and the presence of the classical warning signs of severe and complicated $P$. falciparum malaria. Therefore, these parameters and indices could be useful as predictors of severity in the clinical approach of patients with malaria caused by $P$. vivax. Nevertheless, studies with appropriate methodology to measure prognostic outcomes are required to confirm the efficacy of these indices in clinical practice.

\section{Competing interests}

The authors declare that they have no competing interests.

\section{Authors' contributions}

FALS coordinated specimen collection and analysis of clinical specimens, statistical analysis, manuscript writing and participated in study design. TOGM and ERAJ participated in specimen collection and oversight for malaria microscopy. AFN, SBRS and NPC performed the clinical evaluation of the included patients. CJFF conceived the study, participated in study design, data analysis, manuscript writing and was the lead study investigator. All authors read and approved the final manuscript.

\section{Acknowledgements}

We are grateful for the financial support provided by CAPES and PRONEX- Malaria Network (FAPEMAT/CNPq).

Received: 14 October 2013 Accepted: 20 December 2013

Published: 27 December 2013

\section{References}

1. Anstey NM, Russell B, Yeo TW, Price RN: The pathophysiology of vivax malaria. Trends Parasitol 2009, 25:220-227.

2. Lacerda MVG, Mourão MPG, Alexandre MAA, Siqueira AM, Magalhães BML, Martinez-Espinosa FE, Filho FSS, Brasil P, Ventura AMRS, Tada MS, Couto VSCD, Silva AR, Silva RSU, Alecrim MGC: Understanding the clinical spectrum of complicated Plasmodium vivax malaria: a systematic review on the contributions of the Brazilian literature. Malar J 2012, 11:12.

3. Gérardin P, Rogier C, Ka AS, Jouvencel P, Brousse V, Imbert P: Prognostic value of thrombocytopenia in African children with falciparum malaria. Am J Trop Med Hyg 2002, 66:686-691.

4. Maina RN, Walsh D, Gaddy C, Hongo G, Waitumbi J, Otieno L, Jones D, Ogutu BR: Impact of Plasmodium falciparum infection on haematological parameters in children living in western Kenya. Malar J 2010, 9(Suppl 3):S4.

5. Rodríguez-Morales AJ, Sánchez E, Vargas M, Piccolo C, Colina R, Arria M: Anemia and thrombocytopenia in children with Plasmodium vivax malaria. J Trop Pediatr 2006, 52:49-51.

6. Franklin BS, Vitorino BLF, Coelho HC, Menezes-Neto A, Santos MLS, Campos FMF, Brito CF, Fontes CJ, Lacerda MV, Carvalho LH: Plasma circulating nucleic acids levels increase according to the morbidity of Plasmodium vivax malaria. PLoS One 2011, 6:e19842.

7. Rizvi I, Tripathi DK, Chughtai AM, Beg M, Zaman S, Zaidi N: Complications associated with Plasmodium vivax malaria: a retrospective study from a tertiary care hospital based in western Uttar Pradesh, India. Ann Afr Med 2013, 12:155-159. doi:10.4103/1596-3519.117624.

8. Gupta NK, Bansal SB, Jain UC, Sahare K: Study of thrombocytopenia in patients of malaria. Trop Parasitol 2013, 3:58-61. doi:10.4103/22295070.113914.

9. Greisenegger S, Endler G, Hsieh K, Tentschert S, Mannhalter C, Lalouschek W: Is elevated mean platelet volume associated with a worse outcome in patients with acute ischemic cerebrovascular events? Stroke 2004, 35:1688-1691.

10. Mirsaeidi M, Peyrani P, Aliberti S, Filardo G, Bordon J, Blasi F, Ramirez JA: Thrombocytopenia and thrombocytosis at time of hospitalization predict mortality in patients with community-acquired pneumonia. Chest 2010, 137:416-420.

11. Boos CJ, Beevers GD, Lip GY: Assessment of platelet activation indices using the ADVIATM 120 amongst "high-risk" patients with hypertension. Ann Med 2007, 39:72-78.

12. Jackson SR, Carter JM: Platelet volume: laboratory measurement and clinical application. Blood Rev 1993, 7:104-113.

13. Akpinar L, Sayin MR, Gursoy YC, Karabag T, Kucuk E, Buyukuysal MC, Aydin M, Haznedaroglu IC: Plateletcrit: a platelet marker associated with saphenous vein graft disease. Herz 2013: . Epub ahead of print, doi: 10.1007/s00059-013-3798-y.

14. Sahin F, Yazar E, Yıldız P: Prominent features of platelet count, plateletcrit, mean platelet volume and platelet distribution width in pulmonary tuberculosis. Multidiscip Resp Med 2012, 7:38.

15. Jagroop IA, Clatworthy I, Lewin J, Mikhailidis DP: Shape change in human platelets: measurement with a channelyzer and visualization by electron microscopy. Platelets 2000, 11:28-32.

16. Becchi C, Al Malyan M, Fabbri LP, Marsili M, Boddi V, Boncinelli S: Mean platelet volume trend in sepsis: is it a useful parameter? Minerva Anestesiol 2006, 72:749-756.

17. Gasparyan AY, Ayvazyan L, Mikhailidis DP, Kitas GD: Mean platelet volume: a link between thrombosis and inflammation? Curr Pharm Des 2011, 17:47-58.

18. Lancé MD, Sloep M, Henskens YMC, Marcus MAE: Mean platelet volume as a diagnostic marker for cardiovascular disease: drawbacks of 
preanalytical conditions and measuring techniques. Clin App/ Thromb Hemost 2012, 18:561-568.

19. Ladhani S, Lowe B, Cole AO, Kowuondo K, Newton CRJC: Changes in white blood cells and platelets in children with falciparum malaria: relationship to disease outcome. Br J Haematol 2002, 119:839-847.

20. Coelho HCC, Lopes SCP, Pimentel JPD, Noqueira PA, Costa FTM, Siqueira AM, Melo GC, Monteiro WM, Malheiro A, Lacerda MVG: Thrombocytopenia in Plasmodium vivax malaria is related to platelets phagocytosis. PLoS One 2013, 8:e63410.

21. Chandra S, Chandra H: Role of haematological parameters as an indicator of acute malarial infection in Uttarakhand state of India. Mediterr J Hematol Infect Dis 2013, 5:e2013009.

22. Novelli EM, Hittner JB, Davenport GC, Ouma C, Were T, Obaro S, Kaplan S, Ong'echa JM, Perkins DJ: Clinical predictors of severe malaria anemia in a holoendemic Plasmodium falciparum transmission area. Br J Haematol 2010, 149:711-721.

23. WHO: Guidelines for the treatment of malaria. 2nd edition. Geneva: World Health Organization; 2010.

24. Bashawri LAM, Mandil AA, Bahnassy AA, Ahmed MA: Malaria: hematological aspects. Ann Saudi Med 2002, 22:372-376.

25. Thon JN, Italiano JE: Does size matter in platelet production? Blood 2012, 120:1552-1561.

26. Van der Lelie J, Von dem Borne AK: Increased mean platelet volume in septicaemia. J Clin Pathol 1983, 36:693-696.

27. Singer CR, Walker JJ, Cameron A, Fraser C: Platelet studies in normal pregnancy and pregnancy-induced hypertension. Clin Lab Haematol 1986, 8:27-32.

28. Vatankulu MA, Sonmez O, Ertas G, Bacaksiz A, Turfan M, Erdogan E, Tasal A, Kul S, Uyarel H, Goktekin O: A new parameter predicting chronic total occlusion of coronary arteries: platelet distribution width. Angiology 2013: . epub ahead of print, doi:10.1177/ 0003319713486339.

29. Amin MA, Amin AP, Kulkarni HR: Platelet distribution width (PDW) is increased in vaso-occlusive crisis in sickle cell disease. Ann Hematol 2004, 83:331-335.

30. Dalamaga M, Karmaniolas K, Lekka A, Antonakos G, Thrasyvoulides A Papadavid E, Spanos N, Dionyssiou-Asteriou A: Platelet markers correlate with glycemic indices in diabetic, but not diabetic-myelodysplastic patients with normal platelet count. Dis Markers 2010, 29:55-61.

31. Tozkoparan E, Deniz O, Ucar E, Bilgic H, Ekiz K: Changes in platelet count and indices in pulmonary tuberculosis. Clin Chem Lab Med 2007, 45:1009-1013.

32. Nena E, Papanas N, Steiropoulos P, Zikidou P, Zarogoulidis P, Pita E, Constantinidis TC, Maltezos E, Mikhailidis DP, Bouros D: Mean platelet volume and platelet distribution width in non-diabetic subjects with obstructive sleep apnoea syndrome: new indices of severity? Platelets 2012, 23:447-454.

33. Öztürk ZA, Dag MS, Kuyumcu ME, Cam H, Yesil Y, Yilmaz N, Aydinli M, Kadayifci A, Kepekci Y: Could platelet indices be new biomarkers for inflammatory bowel diseases? Eur Rev Med Pharmacol Sci 2013, 17:334-341.

34. Miller LH, Baruch DI, Marsh K, Doumbo OK: The pathogenic basis of malaria. Nature 2002, 415:673-679.

35. Grynberg P, Fernandes Fontes CJ, Braga EM: Association between particular polymorphic residues on apical membrane antigen 1 (AMA-1) and platelet levels in patients with vivax malaria. Clin Microbiol Infect 2007, 13:1089-1094.

36. Silva SBR: Avaliação da frequência e dos fatores associados a plaquetopenia causada pelo Plasmodium vivax. In MSc ThesisUniversidade Federal do Mato Grosso; 2009. http://www.dominiopublico.gov.br/pesquisa/DetalheObraForm. do?select_action=\&co_obra=185279.

doi:10.1186/1475-2875-12-462

Cite this article as: Leal-Santos et al:: Altered platelet indices as potential markers of severe and complicated malaria caused by Plasmodium vivax: a cross-sectional descriptive study. Malaria Journal 2013 12:462.

\section{Submit your next manuscript to BioMed Central and take full advantage of:}

- Convenient online submission

- Thorough peer review

- No space constraints or color figure charges

- Immediate publication on acceptance

- Inclusion in PubMed, CAS, Scopus and Google Scholar

- Research which is freely available for redistribution

Submit your manuscript at www.biomedcentral.com/submit
C BioMed Central 